\title{
FOCUS GROUP INTERVIEW AS A DATA GATHERING TOOL : ITS APPLICATION TO NURSES' UNDERSTANDING OF HIV INFECTION AND AIDS
}

\author{
NJ Chamane and W Kortenbout
}

\begin{abstract}
The focus group interview ( $F G I$ ) is a research method not commonly used by nurses. It is an effective method if qualitative data are needed and may be used independently to get indepth information, but also can be used in conjunction with tools such as questionnaires, to elicit information that could not be gathered otherwise.

For the FGI to be applied correctly the researcher must be well versed with its contents, and ensure that the primary reason for using such a method is solely to collect data. Other reasons like decision-making or reaching a consensus would not be appropriate.
\end{abstract}

The researcher has shown how this method was used in a study in a specialised hospital in Durban which examined professional nurses' knowledge and understanding of AIDS and $H I V$ infection.

The results not only illustrated knowledge and understanding, but raised sensitive issues and dilemmas related to caring for HIV infected patients. Areas of further research were highlighted and recommen. dations made.

\section{INTRODUCTION}

Focus group interview (FGI) is a type of indepth interview whereby a limited number of interacting individuals with common interests and characteristics relevant to a particular study or topic is used to elicit information that could not be obtained when using other methods of data collection.

Shortly, FGI is a carefully planned discussion. designed to obtain perceptions, on a defined area of interest in a permissive, non-threatening environment. The participants are selected because they have certain characteristics in common that relate to the topic of the focus group. The group members influence each other by responding to ideas and comments in the discussion. Such discussion is not a free-wheeling conversation among group members, but has focus and a clearly identifiable agenda. (Krueger 1988:18 ; Stewart 1990: 10-18; Polit \& Hungler 1991: 279-280)

In the following discussion, the FGI is applied in a study carried out in 1993 in order to examine professional nurses' knowledge and understanding of AIDS and HIV infection.

\section{REVIEW OF LITERATURE}

\section{PURPOSE OF THE FOCUS GROUP INTERVIEW}

\section{Exploratory}

It is advisable where little is known about the topic/ problem. FGI directly taps into human tendencies like attitudes and perceptions, thus eliciting information that may not be available when using other methods of data collection.

It can be used during the same time as a quantitative procedure when indepth information is needed (triangulation). This would yield both depth and breadth of information and enhance the validity of the study (Morgan 1993:24)

\section{Pilot}

FGI can be used as a starting point for the design of survey questionnaires because it helps provide a means for exploring the ways potential participants talk about objects and events. This material will help in identifying alternatives for closed-ended survey items and enable the researcher to identify clues about special problems that may develop in the quantitative data collection phase

Further, this will help in determining the suitability of various types of scaling approaches.

(Krueger 1988:31; Morgan 1993:23; Stewan 1990:16)

\section{Confirmatory}

This kind of interview breaks the tendency to make assumptions about human behaviour, things and reality in general and may be done during the course of a programme to test effectiveness and perceptions of such a programme. On recruitment of new clientele into the existing programme, one can use such a method to get perceptions and feelings about the programme at hand. (Krueger 1988:34 ; Morgan 1993:23)

\section{Evaluation}

When the core aim is to evaluate a programme, one uses the FGI at the end of the programme (summative evaluation) or following certain incidents and procedures. These include :-

- patient care : to determine how the recipients view the kind of care given.

- new product : post use, to evaluate how subjects felt about the new product.

- exit interview : to understand the organisational image.

- as a follow-up to a postal survey. (Krueger 1988:36 \& Stewart1990:15)

FGI as an independent method

This is helpful when insights, perceptions and explanations are more important than numerical information.

(Krueger 1988:31-40 ; Morgan 1993:1-4 \& Stewar 1990: 10-18)

How to use the FGI

Before one attempts to use a FGI one should know what it entails. This includes the following:-

a) People

Participants range from $4-12$, but too few or too many participants would jeopardise the study in various ways such as fragmentation into smaller groups if the number is large, whilst if too few people 
are involved, this would interfere with opening-up for indepth information.

\section{b) Characteristics}

Participants should be:-

- homogenous :- this would be determined by the purpose of the study. The participants are informed of their similarities prior starting the interview, so that they would not be anxious about being chosen.

- unfamiliar with each other since familiarity tends to inhibit disclosures. (Krueger 1988: 27-28)

\section{c) Data Collection Procedure}

This method should examine perceptions, feelings and the manner of thinking of participants.

\section{d) Qualitative Data}

Such data produce insight to attitudes, perceptions and opinions of participants. The results are promoted by the fact that the interview takes place in a natural environment and the participants influence each other. (Krueger 1988: 29-31)

\section{STEPS}

\section{a) Problem Statement}

This includes definition and formulation of research questions. It is at this stage that the researcher decides what kind of information is needed and from whom it should be collected.

\section{b) Sample and Sampling Method}

This should be representative of the whole population. The purposive sampling method is used. One can avoid bias in using this method by further randomly selecting the participants who will participate in various groups. When FGI is used with other methods, one should ensure that the focus group participants do not contaminate other methods. In the application used, the focus group participants were selected after the selection of questionnaire participants. (Polit \& Hungler 1991: 260 ; author's opinion)

\section{c) Moderator}

It is advisable to have a moderator who is knowledgable and well-versed with the topic at hand. The moderator's function is to facilitate the inteview and may be a person who is is employed solely to conduct FGI or the researcher can get involved actively in the data collection procedure and act as moderator. d) Interview Guide

The guide helps to make sure that the desired direction is followed during the interview, and that all aspects are covered. There could be a list of issues for discussion, and could contain one or two open-ended questions. (Stewart 1990: 51-55)

\section{e) Sampling and Recruitment of} Participants

The participants should know the purpose of the study. Stewart (1990) recommends the use of incentives as a compensation for time spent in the focus group which may include giving up of lunch time. (Stewart 1990:55)

\section{f) Conducting the Interview}

This will be further explained in the application used.

\section{g) Analysis and Interpretation of Data}

Since this is a qualitative method, numerical data are not necessary. Data are interpreted by a content analysis and categorising themes, ideas and opinions expressed by the various groups.

\section{THE STUDY: FGI APPLIED AS A RESEARCH TOOL}

The purpose of this study was to determine professional nurses' knowledge and understanding of AIDS and HIV infection. To this end, research was carried out in a specialised Durban hospital during 1993. The FGI was used prior to the questionnaire method, to ensure triangulation and to elicit information that could not be gathered by other methods. The goup participants were registered nurses who were not going to be included in the questionnaire data-collecting method and were chosen by purposive sampling. This helped in avoid study contamination. Initially the focus group was to be formed by 24 participants but at the end only 21 turned up. Participants were chosen randomly for the 3 interview groups.

\section{Realisation of the Study}

Three groups were interviewed. Two groups were formed by 8 participants, and the third group was formed by 5 nurses as it coincided with the pay day and respondents were rushing to go to town during their lunch hour. The interview was carried out in a central place accessible to all participants, and was perceived by them to be non-threatening.

Prior to the interview, verbal consent was obtained from all participants. The purpose of the study was explained, and the reason for the FGI was explained. The tape recorder, recommended by Stewart (1990), was not used. This was due to the political situation and general instability throughout the whole community since it was the transitional period prior to the new government. Instead, with participants' permission, key points/words used during the discussion were documented in writing. Total confidentiality was assured as results would under no circumstances state the participants name.

\section{Theoretical Framework}

Two theories were combined to form a conceptual framework. These were:-

\section{a) Cognitive Dissonance Theory}

This theory assumes that people want to maintain consistency in their beliefs, attitudes, values and behaviour. If individuals confront examples of their own inconsistency in these areas, they will experience psychological discomfort and be motivated to eliminate the inconsistency. (Wicklund \& Brehim, 1976).

\section{b) Fear of Contagion}

This is an affective stress-response to illness. Fear of contagion is an anxiety response to perceived threat of catching the disease. Three behaviours characterise this fear:

- avoidance, taking extreme precautions, verbal expression of fear regarding the disease. (Meisenhelder \& La Charite, 1989)

Both theories were combined and used in exploring the nurses' knowledge and understanding of the problem. The discussion was directed forward eliciting characteristics of fear, avoidance, uncertainty, dissonance/discomfort, knowledge and actual perceptions of various aspects of the disease

\section{RESULTS}

\section{Knowledge}

The discussion focused on professional nurses knowledge and perceptions of AIDS and HIV infection. Due to the fact that the interviews were in group form, the results were not put in numerical form but words like majority, some and few were used. The majority of the nurses could differentiate between AIDS and HIV infection, although some could not state the different stages. The nurses identified a need for intense education on AIDS/HIV infection, to be given on an on-going basis so as to keep them up to date.

\section{Fears}

Almost all participants expressed fear of contracting the disease. The expressed fear was three-fold :- 
- more than half had fear of catching the disease at the workplace.

- all had fear of contracting the infection from the sexual partner, since general appearance could not tell of a person's seropositivity, especially during the early stages.

- all expressed fear of undergoing the test which makes one "know" of one's sero-positivity.

All three groups believed that people do not die because of advancement of the disease but because of "knowing" and the depression associated with the disease.

\section{Dissonance}

The discussion revealed uncertainty and discomfort as far as the universal precautions against infection are concerned. The participants excused themselves for lack of knowledge and gave the reason that they have not yet done the AIDS counselling course. But further to that they expressed confusion that was perperuated by new discoveries that occur from time to time. The discomfort was further increased by the fact that the virus lives even on a dead body. On exploring the feeling about the use of plastic bags for the deceased, the majority felt uncomfortable, since that was seen as interfering with socio-cultural customs of the family concerned. It was also felt that the practice meant disclosure of the diagnosis. This is an area in need of further research.

\section{Confidentiality}

All participants were worried and uncomfortable about the use of plastic bags as they felt that this raised suspicions from people since dead bodies are not usually wrapped in plastic. It was felt that this practice actually breaks the so called" confidentiality".

\section{Search for Cure}

There were a number of participants who believed that there is a herbal cure for the disease and it was felt that the traditional healers should be encouraged to come forward with their herbal treatment. Participants felt that although the herbal treatment is said to be available, it is difficult for the traditional healers to come forward because they are not consulted and involved in healthcare. An aspect of exploitation was also raised whereby it was felt that the traditional healers have in the past discovered herbs that are used to cure certain diseases, and these have been translated to Western medicine with no recognition given to the traditional healer concerned. This is another area for further research

\section{Dilemmas}

A number of issues were raised that could be classed as dilemmas for these professional nurses who saw no clear cut solutions to these.
The dilemma that could not be resolved was that of rape victims who test HIV positive. The nurses felt helpless as far as that was concerned.

The second dilemma was that of sero-positive patients who get discharged still bearing the "revenge" attitude and therefore continue to spread the disease since they "do not want to die alone".

The third dilemma was about those who live on casual sex and the risks associated with such practices.

The fourth dilemma was about blood transfusion, everybody felt threatened about the "unreliable" screening done in the blood banks, further complicated by the window period.

\section{The Use of Condoms}

On exploring the beliefs and attitudes about condom use, it was discovered that condoms had not yet gained total acceptability, even amongst the nursing staff. There was a strong cry for female condoms (femidom) to be made available in South Africa. There seems to be a problem as far as the female condom is concemed, since apart from the expense and the unavailability of this condom, the partner needs to be informed about it.

\section{RECOMMENDATIONS FROM THE THREE GROUPS}

1. All groups recommended breaking of confidentiality issues. It was felt that if HIV infection could be like other infections, it would be easier to render the necessary care, and affected persons would have more courage to come forward for help.

2. Notification of the disease was another issue. The group felt that if the disease could be notifiable management would be easier although it is known that such a matter is difficult, particularly as a cure is not yet available.

3. Informing the community at large about condom use, since condoms appeared not to have gained acceptability even to nursing staff.

4. Setting up a campaign recruiting the traditional healers to divulge potential cures.

5. Trying of various teaching methods to ensure acknowledgement of the disease, since there are still people who deny its existence.

6. Delivering an intensive educational programme on AIDS and HIV infection to the community at large and evaluating the available teaching aids and strategies. to ensure their effectiveness.
7. The inclusion of counselling in the curriculum for basic nurse training.

\section{CONCLUDING STATEMENT}

The FGI can contribute to the knowledge base in the health sciences as illustrated by the above presentation of this method and its application.

\section{REFERENCES}

Akisanya, J.A., \& Rouse, P. (1992). Who will care? A survey of knowledge and attitude of hospital nurses to people with AIDS/HIV Journal of advanced Nursing, $17400-401$

Bailey, K.D., (1978). Method of Social Research New York: Mac Millan.

Burns, N. \& Groove, S.K, (1987). The Practice of Nursing Research, Critique and Utilisation. London: W.B. Saunders Company

Eysenck, M.W, (1992). ANXIETY: The Cognitive Perspective. United Kingdom: Sage Publications.

Krueger, RA. (1988). Focus Group: A Practica Guide for Applied Research. Newbury Park: Sage Publications.

Meisenhelder, J.B. \& LaCharite, C.L. (1989) Fear of Contagion: A stress-response to acquired immunodeficiency syndrome. Advances in Nursing Science 11 (2), 29-37.

Morgan, D.L. (1993). Successful Focus Group Advancing the State of the Art. Newbury Park Sage Publications.

Polit, D., \& Hungler, B., (1989). Nursing Research: Principles and Methods. 3rd Edition. Philadelphia/Toronto: J.B. Lippincot Company.

Stewart, D.W, (1990). Focus Group. Theory and Practice: Applied Social Research Methods Series. Newbury Park: Sage Publications.

Wicklund, R.A., \& Brehim, J.W. (1976) Perspective on Cognitive dissonance. New York: Lawrence Erlbaum Associate Publishers

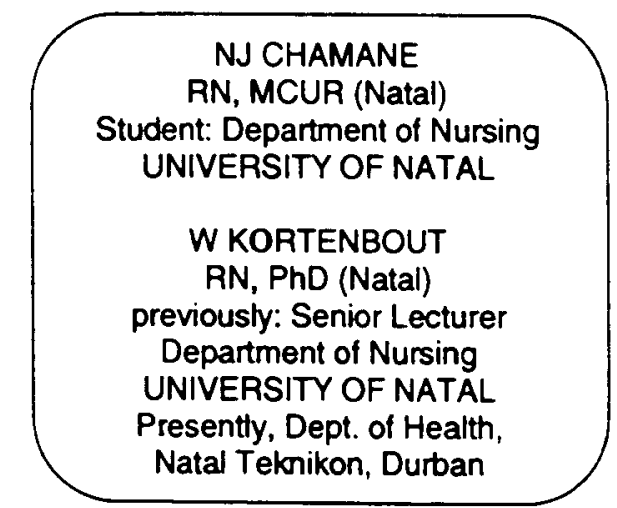

